\title{
Ultra-thin strut cobalt chromium bare metal stent usage in a complex real-world setting. (SOLSTICE registry)
}

\author{
M. J. Suttorp • P. R. Stella • J. Dens • J. M. McKenzie • K. S. Park • \\ $P$. Frambach $\cdot$ on behalf of the SOLSTICE investigators
}

Published online: 7 January 2015

(C) The Author(s) 2014. This article is published with open access at Springerlink.com

\begin{abstract}
Aim To report clinical follow-up at 6 months after implantation of the ultra-thin strut cobalt chromium SolarFlex stent in a real-world setting.

Methods and results Patients $(n=240)$ with single or multiple vessel coronary artery disease undergoing percutaneous coronary intervention (PCI) at four sites in Europe were enrolled in the SOLSTICE (SolarFlex $\underline{\text { Stent in Routine Clinical Practice) }}$ registry. Follow-up at 6 months was $100 \%$. Diabetes was present in $29 \%$ of the patients, $30 \%$ presented with acute myocardial infarction and $17 \%$ had unstable angina. Of the patients, $27 \%$ had previously undergone PCI or coronary artery bypass surgery. Lesion complexity was high $(50 \%$ $\mathrm{B} 2+\mathrm{C}$ type lesions). Device success was achieved in $99.7 \%$ of cases and the major adverse cardiac event (MACE) rate was $5.8 \%$ at 6 months of follow-up. Target lesion revascularisation (TLR) was $5.0 \%$ at 6 months.
\end{abstract}

M. J. Suttorp

Department of Interventional Cardiology, St. Antonius Hospital, Nieuwegein, the Netherlands

P. R. Stella

Department of Cardiology, University Medical Center Utrecht Utrecht University, Utrecht, the Netherlands

J. Dens

Department of Interventional Cardiology, Hospital Oost-Limburg, Genk, Belgium

J. M. McKenzie

DISA Vascular, Cape Town, South Africa

K. S. Park

Strait Access Technologies, Cape Town, South Africa

P. Frambach $(\bowtie)$

Institut National de Chirurgie Cardiaque et de Cardiologie Interventionnelle, Luxembourg, Luxembourg

e-mail: peterframbach@hotmail.com
Conclusions The SOLSTICE registry showed that in a complex real-world setting the SolarFlex bare metal stent, with ultra-thin struts and customised scaffolding, provided low clinical MACE and TLR rates. These results provide support for the use of the latest generation bare metal stent in contemporary European practice.

Keywords Bare metal stent - Cobalt chromium stent . Stent design

\section{Introduction}

Current clinical trials have shown that bare metal stents (BMS) are generally associated with restenosis rates of between 10 and $15 \%$. [1-3]. Drug-eluting stents (DES) have been widely adopted as the device of choice for the treatment of coronary artery disease (CAD) and have proved to be more efficacious than BMS, with clinical restenosis rates dropping to below $10 \%$ [4]. However, many DES systems are limited in terms of flexibility and deliverability, increased costs relative to BMS, and the continued risk of late and very late stent thrombosis [5-7].

While DES are inherently less prone to restenosis than BMS, ongoing developments in understanding the interplay between stent design and clinical outcomes provide scope for narrowing the efficacy gap between BMS and DES, especially in larger vessels where the restenosis rates of DES and BMS already begin to converge [8]. Clinical studies such as the ISAR STEREO and ISAR STEREO II trials have demonstrated the significant advantage of thinner stent struts in reducing restenosis rates [1,2], and first-generation cobalt chromium (Co-Cr) stents allowed stent designs with much thinner struts compared with the older stainless steel stents. Early generation $\mathrm{Co}-\mathrm{Cr}$ stents had a strut thicknesses of 81-91 $\mu \mathrm{m}$. While these dimensions likely conferred some efficacy benefits, a number 
of studies $[1,2,6,9,10]$ have shown that optimal strut dimensions should remain below $75 \mu \mathrm{m}$ in order to ensure rapid endothelialisation of the implant, which in turn is believed to decrease neointimal proliferation.

The primary aim of this post-market, non-randomised, multi-centre, prospective SOLSTICE (SolarFlex Stent in Routine Clinical Practice) registry was thus to assess the safety and efficacy of an ultra-thin strut $\mathrm{L} 605 \mathrm{Co}-\mathrm{Cr}$ bare metal stent, the SolarFlex, in a real-world setting.

\section{Methods}

Data collection and monitoring

The study protocol was approved by the Ethics Committee at each site and each patient provided written informed consent. Patient demographics, presenting conditions, risk factors and procedural outcomes were recorded on Case Report Forms (CRF) at baseline and all major adverse cardiac events (MACE), were recorded in-hospital and at follow-up. CRFs were monitored and reviewed by an independent Clinical Research Associate (CRA) and all reported MACE were reviewed by an independent arbitrator.

\section{Patient population}

Patients older than 18 years of age, with lesion lengths of $25 \mathrm{~mm}$ or less, where a maximum of three de novo or (nonstented) restenotic lesions could be planned to each be fully covered by a single stent, were included in the registry. The following exclusion conditions applied: refractory lesions that could not be pre-dilated at $20 \mathrm{~atm}$; cardiogenic shock; known contraindications or allergy to aspirin, antiplatelet treatment or the stent material; did not qualify for treatment with the necessary concomitant medication; pregnancy; left main disease; history of previous in-stent restenosis; implantation of a drug-eluting stent in the study artery during the same procedure.

Initially 243 patients provided consent but according to the completed CRFs three patients did not meet all the inclusion and exclusion criteria and thus data were collected for the 240 patients who did fully met the criteria.

Balloon angioplasty and stent implantation were performed according to standard clinical practice in the participating centres and the recommendations of the SolarFlex Instructions for Use. Criteria for whether to implant a BMS or a DES were based on the current practices of each particular site. It was recommended that an appropriate dual antiplatelet regimen should be strictly adhered to for at least 30 days after the intervention.
The SolarFlex stent system

The SolarFlex stent system consists of a cylindrical, electropolished, Co-Cr corrugated ring balloon-expandable stent mounted on a rapid-exchange coronary stent delivery catheter. The stent has an ultra-thin strut thickness down to $65 \mu \mathrm{m}$. Five different stent cellular configurations are used to span the five diameters of the full range, as illustrated in Fig. 1 (stents range from 12 struts around the circumference for $2.5 \mathrm{~mm}$ stents to 20 struts around the circumference for $4 \mathrm{~mm}$ stents). The stent system was available in $2.5,2.75$, $3.0,3.5$ and $4.0 \mathrm{~mm}$ diameters and 11, 14, 17, 20, 24 and $28 \mathrm{~mm}$ lengths. The stent has a low crimped profile down to 0.84 for $2.5 \mathrm{~mm}$ stents.

\section{Definitions}

Clinically driven target lesion revascularisation (cTLR) was defined as any repeat percutaneous intervention of the study stent or bypass surgery of the target vessel due to symptoms or functional evidence of ischaemia in the presence of a percent diameter stenosis $\geq 50 \%$, or percent diameter stenosis of $\geq 70 \%$ even in the absence of ischaemic signs or symptoms.

MACE was defined as the composite of cardiac death, myocardial infarction (MI) attributable to the target vessel, and cTLR. Any deaths due to proximate cardiac cause, unwitnessed death and death of unknown cause, and all procedure-related deaths, including those related to concomitant treatment, were classified as cardiac death. MI was defined as the presence of elevated troponin $\mathrm{T}$ or troponin I greater than three times the upper limit of normal. Stent thrombosis (definite or probable) was defined using the Academic Research Consortium definition [11].

Device success was defined as the ability to reach and cross the target lesion, deploy the stent and withdraw the stent delivery catheter, with the attainment of a post-stent diameter residual stenosis $\leq 30 \%$ with $\geq$ TIMI 2 flow with the treatment device alone; standard pre-dilation and post-dilation catheters could be used. Procedural success was defined as device success with freedom from in-hospital MACE.

\section{Follow-up}

All patients were followed up for 6 months after treatment either by clinical examination by the investigator or a telephone interview. Interviews were used to evaluate the occurrence of cTLR and MACE within the follow-up period.

Statistical analysis

Continuous variables were presented as mean \pm standard deviation and categorical variables were presented as counts and percentages. 
Fig. 1 Schematic illustration showing the uniform distance between stent struts over all five stent sizes

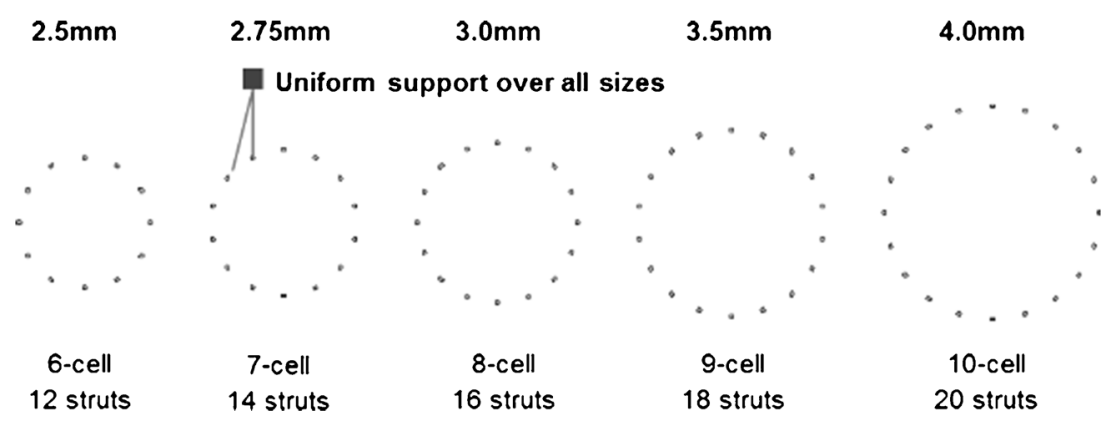

\section{Results}

Patient demographics

Four European centres enrolled 240 patients who met all the inclusion and exclusion criteria in the period from April 2011 to January 2012. The average age of the patients was 66 years, with the majority being male (74\%). Over one-quarter of patients $(29 \%)$ were diabetic. A notably large number (30\%) of patients presented with acute MI (AMI). The full patient demographics and baseline clinical characteristics are given in Table 1.

\section{Angiographic characteristics}

The baseline angiographic characteristics are shown in Table 1 . The vessels treated were primarily the left anterior descending artery (36\%) and right coronary artery (37\%). Significantly, over $50 \%$ of lesions were categorised as complex (B2 + C type) according to the modified American College of Cardiology (ACC) and the American Heart Association (AHA) classification [12].

\section{Procedural characteristics}

In total 292 lesions were treated with 293 stents, representing 1.2 stents per patient. Pre-dilatation was performed in $60 \%$ of the lesions while post-dilatation was carried out in $21 \%$ of the lesions. The reason for stenting was primarily elective $(90 \%)$. The average stent diameter used was $3.15 \mathrm{~mm}$ with an average length of $17.47 \mathrm{~mm}$. All devices reached the target lesion and a $99.7 \%$ device success rate was achieved. The procedural success rate was $97.5 \%$. Procedural data are recorded in Table 2.

\section{Clinical follow-up}

Follow-up at 6 months was $100 \%$ The cumulative rate of cTLR at 6 months was $5.0 \%$. A single case of cardiac death occurred before 30 days which, by definition, was attributed to a probable stent thrombosis. This patient was a 77-year-old male smoker with a previous history of MI who presented with unstable angina and who died of unknown causes 1 week after PCI. A second patient died of non-cardiac related causes (thus not considered a MACE). Total MACE at 6 months was $5.8 \%$.

\section{Discussion}

While DES continue to be more efficacious than BMS, patients treated with BMS for such reasons as limited financial resources or contraindication to dual antiplatelet therapy still have excellent outcomes in modern clinical practice. This is demonstrated through ongoing BMS registries and metaanalyses and thus continues to warrant further study of BMS [13].

A review of all multi-centre registries or clinical trials of single $\mathrm{Co}-\mathrm{Cr}$ stent types with more than 100 patients and 6 9 month follow-up was carried out to analyse the results from the SOLSTICE study in the context of other Co-Cr bare metal stents. (Note that studies restricted to patients presenting with STEMI were also excluded from this review). A comparison of the key results of these studies is shown in Table 3.

Randomised trials have demonstrated that BMS with thin struts result in lower restenosis rates than thick-strut stents [1, 2]. The current understanding of stent design has also demonstrated the advantages of greater scaffolding support [14]. This is supported by computational fluid dynamics which has shown that increasing the number of struts around the circumference results in a smaller intrastrut area exposed to low wall shear stress [15]. Increased scaffolding comes at the expense of increased metal-to-artery contact, which is thought to exacerbate any foreign body effects of the implant, and a denser crimped configuration. Applying these principles to the SolarFlex stent, a customised scaffold structure was created where each stent diameter has its own cell design to provide uniform support over all artery sizes. The MACE data, while often difficult to compare between studies because of varying definitions, reveal the SolarFlex stent to have a very low MACE rate $(5.8 \%)$ compared with the other studies detailed in Table 3, a fact which may be attributable to the application of these stent design principles. In addition, the cumulative 
Table 1 Baseline clinical and angiographic characteristics

\begin{tabular}{|c|c|}
\hline Number of patients & 240 \\
\hline Age (years) & $66 \pm 12.6$ \\
\hline Male (\%) & $178(74 \%)$ \\
\hline \multicolumn{2}{|l|}{ Baseline angina status } \\
\hline Asymptomatic & $7(2.9 \%)$ \\
\hline Silent ischaemia & $12(5.0 \%)$ \\
\hline Stable & $108(45.0 \%)$ \\
\hline Unstable & $40(16.7 \%)$ \\
\hline AMI & $73(30.4 \%)$ \\
\hline \multicolumn{2}{|l|}{ History of } \\
\hline MI & $67(27.9 \%)$ \\
\hline CABG & $16(6.7 \%)$ \\
\hline PCI & $71(29.6 \%)$ \\
\hline \multicolumn{2}{|l|}{ Risk factors } \\
\hline Diabetes mellitus type 1 & $38(16 \%)$ \\
\hline Diabetes mellitus type 2 & $31(13 \%)$ \\
\hline Hypertension & $138(58 \%)$ \\
\hline Cholesterol & $142(59 \%)[n=239]^{\mathrm{a}}$ \\
\hline Family history & $114(48 \%)[n=237]^{\mathrm{a}}$ \\
\hline Smoking & $186(22 \%)[n=238]^{\mathrm{a}}$ \\
\hline Number of lesions & 292 \\
\hline \multicolumn{2}{|l|}{ Target lesion classification } \\
\hline A & $50(17.1 \%)$ \\
\hline B1 & $92(31.5 \%)$ \\
\hline $\mathrm{B} 2$ & $110(37.7 \%)$ \\
\hline $\mathrm{C}$ & $37(12.7 \%)$ \\
\hline Unknown & $3(1.0 \%)$ \\
\hline \multicolumn{2}{|l|}{ Vessels treated } \\
\hline Heft anterior descending & $106(36.3 \%)$ \\
\hline Right coronary artery & $108(37.0 \%)$ \\
\hline Circumflex & $74(25.3 \%)$ \\
\hline Saphenous valve graft & $3(1.0 \%)$ \\
\hline Ramus & $1(0.3 \%)$ \\
\hline \multicolumn{2}{|l|}{ Angulation } \\
\hline$<45^{\circ}$ & $236(80.8 \%)$ \\
\hline$\geq 45^{\circ}$ & $47(16.1 \%)$ \\
\hline$\geq 90^{\circ}$ & $7(2.4 \%)$ \\
\hline Unknown & $2(0.7 \%)$ \\
\hline \multicolumn{2}{|l|}{ Tortuosity } \\
\hline Low & $186(63.7 \%)$ \\
\hline Moderate & $86(29.5 \%)$ \\
\hline High & $18(6.2 \%$ \\
\hline Unknown & $2(0.7 \%)$ \\
\hline \multicolumn{2}{|l|}{ Complexities } \\
\hline Bifurcation & $35(12.0 \%)$ \\
\hline Ostial & $15(5.1 \%)$ \\
\hline Thrombus & $32(11.0 \%)$ \\
\hline Calcification & $77(26.4 \%)$ \\
\hline Diffuse disease & $32(11.0 \%)$ \\
\hline Involves side branch & $12(4.1 \%)$ \\
\hline
\end{tabular}

${ }^{a}$ Where data were not available for all patients the number of patients with data is indicated (n)
Table 2 Clinical outcomes

\begin{tabular}{|c|c|}
\hline Number of stents & 293 \\
\hline \multicolumn{2}{|l|}{ Average stent dimensions } \\
\hline Diameter (mm) & $3.15 \pm 0.38$ \\
\hline Length (mm) & $17.47 \pm 4.82$ \\
\hline Predilation & $176(60.1 \%)$ \\
\hline Direct stenting & $117(39.9 \%)$ \\
\hline Post-dilation & $60(20.5 \%)$ \\
\hline \multicolumn{2}{|l|}{ Reason for stenting } \\
\hline Elective & $265(90.4 \%)$ \\
\hline Dissection & $23(7.8 \%)$ \\
\hline Other & $5(1.7 \%)$ \\
\hline Delivery success (stents reaching lesion) & $293(100 \%)$ \\
\hline Device success (per stent) & $292(99.7 \%)$ \\
\hline Procedural success (per patient) & $234(97.5 \%)$ \\
\hline Follow-up & $240(100 \%)$ \\
\hline \multicolumn{2}{|l|}{ In-hospital events } \\
\hline Total MACE & $5(2.1 \%)$ \\
\hline Cardiac death & 0 \\
\hline Myocardial infarction & $1(0.4 \%)$ \\
\hline Target lesion revascularisation & $4(1.7 \%)$ \\
\hline Stent thrombosis (definite) & $3(1.3 \%)$ \\
\hline \multicolumn{2}{|l|}{ 6-month outcome (cumulative) } \\
\hline Total MACE & $14(5.8 \%)$ \\
\hline Cardiac death & $1(0.4 \%)$ \\
\hline Myocardial infarction & $3(1.2 \%)$ \\
\hline Target lesion revascularisation & $12(5.0 \%)$ \\
\hline Stent thrombosis (probable) & $1(0.4 \%)$ \\
\hline Stent thrombosis (definite) & $4(1.7 \%)$ \\
\hline
\end{tabular}

TLR results for the study $(5.0 \%)$ compare favourably with other studies in the selection (bar that of the study of the Vision stent carried out by $\mathrm{Xu}$ et al. [16] which appears to have an atypical cTLR rate of $1.4 \%$ when compared with the other studies of this same stent carried out by Kereiakes et al. [17] and Brambilla et al. [18] which have TLR rates of 4.3 and $5.8 \%$ respectively. It should be noted that the mean stent diameter in our study was above $3.0 \mathrm{~mm}$ and the mean stent length was below $20 \mathrm{~mm}$, which predict relatively low rates of restenosis. The sizes of the SolarFlex in the study do, however, fall within the same range as the other studies.

While substantially more data have been collected on L605 Co-Cr stents that other Co-Cr alloys, choosing L605 as BMS material may provide clinical advantages. The average TLR rate of the L605 alloy stents is $4.5 \%$ compared with that of $8.5 \%$ for the MP35N alloy, with average MACE rates being 8.3 and $10.4 \%$ respectively. The single study using the Phynox alloy demonstrated a TLR rate of $6 \%$ and a MACE rate of $13 \%$.

While DES tend to suffer from limited deliverability and flexibility (due to the presence of coatings, less firm crimping procedures, and the use of earlier generation BMS platforms) 
Co-Cr BMS have a high delivery success rate as shown for all the studies listed in Table 3. Data relating to the Abbott Vascular (formerly Guidant) Multilink family of stents provides an interesting case study to demonstrate the evolution of deliverability for $\mathrm{Co}-\mathrm{Cr}$ stents to parallel improved clinical data for its Co-Cr Multilink Vision stent. A decade ago, Kereiakes et al. [17] showed, for this family of stents, that late lumen loss is related to strut thickness, and that the relative biocompatibility of $\mathrm{Co}-\mathrm{Cr}$ is also supported by this data. Interestingly, as Ormiston et al. show [19], a steady reduction in crossing profile has been linked to improved deliverability, with the early generation Multilink stent having a crossing profile of $1.53 \mathrm{~mm}$ showing worse trackability than the Multilink Duet, which has a crossing profile in the order of $1.17 \mathrm{~mm}$, despite both systems having similar flexibility. The continued pursuit of improved deliverability has thus driven profiles for commercial stents down even further to the order of $1 \mathrm{~mm}$ [20], with the SolarFlex $3.5 \mathrm{~mm}$ delivery system having a crimped profile of $0.98 \mathrm{~mm}$. A relatively high direct stenting rate in the complex real-world setting of this SOLSTICE study of $39.9 \%$, together with a delivery success rate of $100 \%$, supports this evidence for efficient deliverability of a BMS ultra-thin strut Co-Cr system. The technological improvements related to BMS deliverability have kept pace with improvements in clinical outcome.

Four cases of definite stent thrombosis were recorded during the SOLSTICE study and an interrogation of these cases reveals that all four of the patients presented with AMI. While the mechanism of stent thrombosis is not limited to a single factor (various factors related to the procedure, lesion and patient are relevant), it is known that patients presenting with AMI have an increased risk of stent thrombosis [21].

\section{Study limitations}

A lack of angiographic follow-up can represent a study limitation; however, clinical endpoints, as used in the SOLSTICE study, are possibly of more relevance for assessment of patient outcomes. Although lack of randomisation is a limitation, the study sought to examine real-world clinical safety and effectiveness in a milieu of proven DES superiority. Approximately 2840 PCIs were performed in the four centres over the study enrolment period, while only 240 patients were enrolled in the registry; selection bias is therefore possible.

\section{Conclusions}

Positive developments in bare metal stent material and design understanding continue to be seen through the improving clinical data being gathered in real-world registries. Judicious use of advanced bare metal stent designs can result in suitable clinical 
outcomes, as is suggested in this study by the low MACE and TLR rates of an ultra-thin strut L605 cobalt-chromium bare metal stent with a customised cell design providing uniform support over all artery sizes in the stent range.

Acknowledgments Principal Investigator: Peter Frambach, Institut National de Chirurgie Cardiaque et de Cardiologie Interventionnelle, Luxembourg

The following investigators participated in the SOLSTICE registry:

Institut National de Chirurgie Cardiaque et de Cardiologie Interventionnelle (INCCI), Luxembourg: P. Frambach, MD (PI), D. Wagner, MD, PhD, Dr B. Pereira, MD.

Hopsital Oost-Limburg (ZOL), Genk, Belgium: J. Dens, MD, PhD, M.C.M. Vrolix, MD,

University Medical Centre (UMC), Utrecht, the Netherlands: P.R. Stella, MD, PhD, P. Agostoni, MD, PhD, M. Voskuil, MD, PhD, F. Spano, MD, B.J.B Hamer, MD, A. El Hosieny, MD, MSc, K. Onsea, MD, T.X. Wildbergh, MD.

St Antonius Hospital, Nieuwegein, the Netherlands: M.J. Suttorp, MD, PhD, A.N. van de Akker, MD, M.A. Bosschaert, MD, M. Harmsen, MD, ET Bal, MD, EG Mast, MD, J ten Berg, MD, PhD, B Rensing, MD, $\mathrm{PhD}$, F Eefting, MD, J van der Heijden, MD, PhD.

Conflict of interest None of the authors have declared any conflict of interest related to the content of this manuscript with the exception of Jean McKenzie who is an employee of DISA Vascular, and Kenneth Park who is a former employee of DISA Vascular.

Funding This work was supported by DISA Vascular and TOP Medical.

Open Access This article is distributed under the terms of the Creative Commons Attribution License which permits any use, distribution, and reproduction in any medium, provided the original author(s) and the source are credited.

\section{References}

1. Kastrati A, Mehilli J, Dirschinger J, et al. Intracoronary stenting and angiographic results: strut thickness effect on restenosis outcome (ISAR-STEREO) trial. Circulation. 2001;103:2816-21.

2. Pache J, Kastrati A, Mehilli J, et al. Intracoronary stenting and angiographic results: strut thickness effect on restenosis outcome (ISAR-STEREO-2) trial. J Am Coll Cardiol. 2003;41:1289-92.

3. Kaiser C, Brunner-La Rocca HP, Buser PT, et al. Incremental costeffectiveness of drug-eluting stents compared with a third-generation bare-metal stent in a real-world setting: randomised Basel stent kosten effektivitäts trial (BASKET). Lancet. 2005;366:921-9.

4. Farooq V, Gogas BD, Serruys PW. Restenosis: delineating the numerous causes of drug-eluting stent restenosis. Circ: Cardio Inter. 2011;4:195-205.

5. Pfisterer M, Brunner-La Rocca HP, Buser PT, et al. Late clinical events after clopidogrel discontinuation may limit the benefit of drug eluting stents: an observational study of drug-eluting versus baremetal stents. J Am Coll Cardiol. 2006;48:2584-91.

6. Daemen J, Wenaweser P, Tsuchida K, et al. Early and late coronary stent thrombosis of sirolimus-eluting and paclitaxel-eluting stents in routine clinical practice: data from a large two-institutional cohort study. Lancet. 2007;369:667-78.

7. Rubboli A, Dewilde W, Huber K, et al. The management of patients on oral anticoagulation undergoing coronary stent implantation: a survey among interventional cardiologists from eight European countries. J Interv Cardiol. 2012;25:163-9.

8. Pache J, Dibra A, Mehilli J, et al. Drug-eluting stents compared with thin-strut bare stents for the reduction of restenosis: a prospective, randomized trial. Eur Heart J. 2006;26:1262-8.

9. Jabara R, Geva S, Ribeiro HB, et al. A third generation ultra-thin strut cobalt chromium stent: histopathological evaluation in porcine coronary arteries. Euro Inter. 2009;5:619-26.

10. Simon C, Palmaz JC, Sprague EA. Influence of topography on endothelialisation of stents: clues for new designs. J Long Term Eff Med Implants. 2000;10:143-51.

11. Cutlip DE, Windecker S, Mehran R, et al. Clinical end points in coronary stent trials. Circulation. 2007;115:2344-51.

12. Ryan TJ, Faxon DP, Funnar PM, et al. Guidelines for percutaneous transluminal coronary angioplasty: a report of the American college of cardiology/america heart association task force on assessment of diagnostic and therapeutic cardiovascular procedures (subcommittee on percutaneous transluminal coronary angioplasty). J Am Coll Cardiol. 1998;12:529-45.

13. Yong AS, Tremmel JA. Can we bear another bare metal stent study? Catheter Cardiovasc Interv. 2013;81:1095-6.

14. Garasic JM, Edelman ER, Squire JC, et al. Stent and artery geometry determine intimal thickening independent of arterial injury. Circulation. 2000;101:812-8.

15. LaDisa JF, Olson LE, Guler I, et al. Circumferential vascular deformation after stent implantation alters wall shear stress evaluated with time-dependent 3D computational fluid dynamics models. J Appl Physiol. 2005;98:947-57.

16. Xu Y, Wei Y, Tang K, et al. Multi-link vision and mini vision stent registry in Asian patients with coronary artery disease: a prospective, multi-center study. Chin Med J. 2007;120:1093-6.

17. Kereiakes DJ, Cox DA, Hermiller JB, et al. Usefulness of a cobalt chromium coronary stent alloy. Am J Cardiol. 2003;92:463-6.

18. Brambilla N, Morici N, Bedogni F, et al. Thin strut chrome-cobalt stent implantation for treatment of de novo lesions in small coronary vessels: results of the RISICO Italian registry (Registro Italiano Mini Vision nei piccolo Vasi) utilizing the mini vision coronary stent platform. J Cardiovasc Med. 2009;10:852-8.

19. Ormiston JA, Dixon SR, Webster MW, et al. Stent longitudinal flexibility: a comparison of 13 stent designs before and after balloon expansion. Catheter Cardiovasc Interv. 2000;50:120-4.

20. Abizaid A. A Novel Multimaterial Stent: Initial Clinical Results. Presentation: EuroPCR 2005.

21. Vlachojannis GJ, Claessen BE, Dangas GD. Early stent thrombosis after percutaneous cornary intervention for acute myocardial infarction. Interv Cardiol. 2012;7:33-6.

22. Vermeersch P, Appelman Y, Horstkotte D, et al. Safety and efficacy of the cobalt chromium PRO-Kinetic coronary stent system: results of the MULTIBENE study. Cardiovasc Revasc Med. 2012;13:316-20.

23. Strehblow C, Gyöngyösi M, Zenker G, et al. Small vessel stenting with cobalt-chromium stents (Arthos Pico) in a real-world setting. Coron Artery Dis. 2007;18:305-11.

24. Bocksch W, Pomar F, Dziarmaga M, et al. Clinical safety and efficacy of the CoroFlex Blue cobalt-chromium stent system: results of the real-world CoroFlex Blue registry. Catheter Cardiovasc Interv. 2010;75:78-85.

25. Giordano A, Polimeno M, Corcione N, et al. Synergy between direct coronary stenting technique and use of the novel thin strut cobalt chromium Skylor stent: the Mace in follow up patients treated with Skylor stent (MILES study). Curr Cardiol Rev. 2012;8:6-13.

26. Sketch MH, Ball M, Rutherford B, et al. Evaluation of the medtronic (Driver) cobalt-chromium alloy coronary stent system. Am J Cardiol. 2005;95:8-12.

27. Legrand V, Kelbaek H, Hauptmann KE, et al. Clinical and angiographic analysis with a cobalt alloy coronary stent (Driver) in stable and unstable angina Pectoris. Am J Cardiol. 2006;97:349-52. 